\title{
MULTICRITERIA INVENTORY CLASSIFICATION IN THE EXPEDITION WAREHOUSE OF THE METALLURGICAL COMPANY
}

\author{
Tomáš MALČIC, Petr BESTA \\ VSB - Technical University of Ostrava, Ostrava, Czech Republic, EU, tomas.malcic@vsb.cz
}

https://doi.org/10.37904/metal.2020.3645

\begin{abstract}
This paper deals with the optimization of storage and retrieval operations in the expedition warehouse of the metallurgical company. First, the problem of warehouse management in the metallurgical industry is defined. In the literature review, the approaches, methods, and results from studies of different authors are presented. In the main part of the paper, the idea of application of the principles and methods from the automotive industry in the metallurgical industry is described. For this purpose, the differences between the logistics processes in these two industries are described. Implementation of multicriteria inventory management for optimization of storage location assignment and subsequently the order picking is proposed. Conclusions from this paper will serve as a foundation for future work centered around the design of multicriteria support tools for decisionmaking processes related to storage and retrieval operations.
\end{abstract}

Keywords: Decision making, metallurgy, multicriteria, storage location assignment, order picking

\section{INTRODUCTION}

In the present market environment, companies need successful supply chain management for maintaining their competitiveness. Key element of the supply chain is the warehouse. Mainly in a manufacturing company a storage is an essential part. This is true especially in the metallurgical industry, because of the specifications and characteristics of it. Factors like large production batches, varied product portfolio and large dimensions of products causes warehouse operations in metallurgical companies to be very complex and resource intensive. Warehouse operations are producing about $20 \%$ of total logistics costs. The most cost-intensive warehouse operation is order-picking. It is labor-intensive and repetitive process which generates up to $60 \%$ of total warehouse costs. Order picking process is still often performed manually. Studies have shown that order pickers spend up to $50 \%$ of their work time traveling between storage locations. From above mentioned, it is apparent that there is huge protentional for significant savings of money and time in optimization of warehouse operations management and especially in order picking. Naturally the best approach for optimizing warehouse operations and minimizing logistics costs is to design a completely new warehouse. This radical approach is mostly impossible, and so the less radical methods must be used. One of these methods is redesign of operational processes. Order picking process efficiency can be increased by the optimization of storage systems and storage allocation. Efficiency of warehouse operations is characterized by the cost reduction, space utilization and total distance traveled. Efficiency of warehouse management also affects the level of logistics services provided to the customer. The solution of storage location determination lays in reduction of the space requirement and minimalization of the total travel distance and time throughout the warehousing process. These two criteria can be conflicting. The various criteria considered while determining the storage location in a warehouse for each product are also often conflicting [1,2].

Order picking requires great portion of attention from warehouse management standpoint, because of its high share on total cost of warehouse operations. Besides the fact it is a cost-intensive activity it is also important due to the direct link to the performance of warehouse and consequently the whole supply chain. Any 
inefficiency in order picking process directly leads to unsatisfactory service for the customer. In order to ensure efficient order picking process, it must be designed and planned in detail. The main areas of focus in designing and planning are layout design, storage assignment, routing, order batching and zoning. The minimalization of order picking time and distance travelled is achieved through the order picking route planning. The performance of order pickers is increased with separation of warehouse into zones. So, the order pickers only operate in their assigned zone. The efficiency of warehouse space utilization is ensured by the dedication of storage location to the stored products based on their occupancy. Other approach to optimization of order picking process is order batching, which reduces the distance travelled [1,2].

This paper deals with increasing efficiency of the order picking process in the expedition warehouse of the metallurgical company. Presented approach focuses on product storage location assignment optimization. General theoretical basis from this are presented. Literature review of scientific publication, mainly papers presented in journals and conference proceedings was performed. Results and findings of different authors dealing with issue of warehouse management were summarized. It was found that for solved problematic there is comprehensive solution in automotive industry. Automotive companies invented and implemented complex and effective storage and retrieval automated systems. Those best practices were analyzed and protentional of their application in the metallurgical industry was explored. Due to significant differences in both industries it is impossible for metallurgical companies to completely adopt practices from automotive industry, but it is possible for them to take inspiration and use similar concepts and technologies. The principles and systems of warehouse operations used in automotive industry must be adjusted to fit the specifications of metallurgical industry.

\section{PROBLEM DEFINITION}

The main issue in the expedition processes of the metallurgical company is inefficient order picking. Redundant warehouse operations such as material manipulations, personnel and equipment movement. are in most cases results of the inefficient stored product allocation in the warehouse. Current storage location assignment methodic consists of predesigned warehouse layout plan and product allocation system. These two elements of warehouse management are closely interconnected. The warehouse layout plan is strategic tool for organization of warehouse management with purpose to optimize space utilization and systematic product placement. The product allocation system is more of an operational tool supporting decision-making process in selection process of storage location for finished products. The decision-making process involves many variables which vary based on the type of stored product, the current state of warehouse, occupancy of storage locations and the requirements and the priorities. This decision-making process is complex and comprehensive problem, which must be supported with various tools and methods. Usage of exact decision-making methods, mathematical modeling, algorithms, digitalization and automatization will ensure the optimal solution for every product. Also, the intuitive and individual nature of decision in warehouse management will be eliminated and whole process will be standardized [3].

Throughout the series of logistics audits performer in metallurgical company a number of causes of waste in warehouse operations were identified. One of the major causes of the identified inefficiencies in warehouse operations was inappropriate system of product storage allocation. The inefficiency of the current system leads to an unsystematic layout of products in the expedition warehouse, which is causing a large number of redundant warehouse operations and an increase in average loading times. Redundant warehouse operations are primarily manipulation with products, product tracing, and multiple loadings. During the literature review, which is presented in the next chapter, number of studies dealing with the issue of product storage, warehouse layout design and order picking. Some of the studies deals with optimization particular warehouse or process. Other studies were more complex and dealt with the issue in more general way and presented solutions for whole supply chains or for selected industry. 
The products storage locations are assigned in relation to planned expeditions and based on the categorization of products according to turnover rate, customer behaviour, production campaign, etc. One of the major problems is the allocation of products from one contract at storage locations distant from each other. Further problem is allocation of products scheduled for expedition soon are stored on storage locations far from the loading place. On the contrary products with low turnover rate are placed at storage locations near loading places, that leaves them unnecessarily occupied for long periods of time. These inefficiencies cause redundant warehouse operations and long routes for personnel and handling equipment during the expedition leading to longer order picking times. Part of the decision-making problem is that not every storage location is suitable for whole product portfolio. This means that the set of suitable storage location must be determined individually for each group of products based on the specifics. And from this determined set the optimal storage place is further selected via multi-criteria decision-making algorithm.

\section{LITERATURE REVIEW}

This chapter will summarize the results of a literature review in the field of warehouse management, layout organization, inventory classification, shipping processes and multicriteria decision-making processes that accompany these areas. Dozens of publications dealing with these areas have been analyzed and those, whose goals and methods are related to the focus of this publication, are presented below. Venkitasubramony and Adil considers the layout design problem in an order-picking rack-based warehouse with turnover-based storage assignment. In their study they also factor vertical travel besides horizontal. The study results with an optimal design of warehouse in terms of manipulation costs and space requirements. The results also contain the solution of problem with algorithm, which is presented on real case study. Venkitasubramony and Adil defines layout design as an important element of warehouse design, which consists of determination of length, width, height, aisle width, position of Pickup/Deposit (P/D) point, etc. They believe that warehouse operational costs are determined mainly at the design stage and are very difficult to change in an already built warehouse. Due to the ever-increasing and changing requirements of customers, manufacturing companies had to abandon conventional production systems and adopt the FMS flexible manufacturing system. FMS uses automated machinery, automated material handling and automated storage and retrieval system (AS / AR). AS / AR plays a very important role in FMS, as handling costs can reach up to $30 \%$ of the total production costs. The implementation of AS / SR requires high investments and therefore the system must work efficiently. Criteria for evaluating the effectiveness of AS / SR are capacity, system throughput, utilization and reliability. Venkitasubramony and Adil propose to improve AS / SR performance using heuristic and genetic algorithms. Venkitasubramony and Adil defines following storage strategies include random storage, dedicated storage, class-based storage, and Duration-of-Stay (DOS) based storage, compare random storage, dedicated storage, and class-based storage in single-command and dual-command AS/RS using both analytical models and simulations [4]. Ene and Öztürk deals with design of storage system in automotive industry warehouse. They are focused on storage assignment and order picking system design optimization via mathematical model and stochastic evolutionary approach. Their work has two stages. In stage on they solve storage assignment problem with a class-based storage policy. In stage two they solve batching and routing problem to minimize warehouse operations costs. They propose solution for optimal batches and optimal routes for order picker based on genetic algorithm with a quick response [5]. Fontana and Cavalcante deals with determination of the best alternative for storage location assignment with use of Promethee method. They use Promethee multicriteria method to solve this problem. With this method they can identify all non-dominated storage locations for the product in the warehouse and can efficiently rank the alternatives in the decision process. Fontana and Cavalcante defines storage as one of the traditional aspects of logistics. And they state that good storage system should facilitate the identification of material and increase productivity and reduce the costs, because of facilitation of the management of inventories. Fontana and Cavalcante defines order picking as the retrieval of stock keeping units (SKUs) from a warehouse to satisfy customer order and views it as a vital component of supply chain. They also state that implementation of order picking strategy is operational 
problem and that the selection of it is a strategic decision. They consider order picking the most critical operation in warehousing. According to Fontana and Cavalcante warehouse storage decisions influence every $\mathrm{KPI}$ of a warehouse from order picking time to the cost of using storage space. They identified two main issues in warehouse planning, which are inventory management and storage location assignment. Optimization of inventory management leads to reducing warehousing costs. Efficient assignment of storage location reduces the travel times for storage/ retrieval and order picking [6]. Jawahar, Aravindan \& Ponnambalam presented the following Storage Location Assignment Rules Pattern search, lower tier first (LTF), Shortest processing time (SPT), Random assignment (RANDOM) and Turnover rate-based zone assignment (ZONE). They also recommended following zoning procedures before implementation class based turnover assignment Fixed zone sizes and locations (FSFL), Fixed zone sizes but moving locations (FSML), Moving zone sizes and locations (MSML) and Equal distant rack zoning (EDR) [7]. Balaji and Kumar dealt with MCIC (multi criteria inventory classification) in an automotive industry. They expanded standard methodology of $A B C$ inventory classification with AHP (analytic hierarchy process) to extend the decision making in inventory management from a single criterion to various criteria, such as turnover-rate, durability, unit price etc. Balaji and Kumar used AHP for analysis of the spare parts of a large manufacturing company and genetic algorithm was used for classification of inventory by criteria like lead time, unit price, reparability, order size, number of requests etc [8]. Manzini, Gamberi and Persona presented an integrated approach to support the decision-making process in optimizing the order picking system (OPS). Their goal is to identify the impact of different approaches and strategies for storing and order picking on the system's response to customer orders. They analyzed hundreds of industrial systems and performed thousands of simulations of various scenarios. Based on the results, they proposed a multiparametric dynamic and analytical model [9]. Šafránek and Sikorová dealt with the issue of analysis and optimization of storage and expedition of products in the expedition warehouse of a metallurgical company. They performed an $A B C$ analysis of the products based on the frequency of their production and for product group $\mathrm{A}$ they also performed an $\mathrm{XYZ}$ analysis based on their turnover rate. Subsequently, they used the results of the analyzes to create a proposal for a new classification of products in the warehouse in order to optimize both the process of storing products and the process of shipping products. They point out the problem with the lack of information about the planned production and propose to support the system by digital visualization of the warehouse in the future and the implementation of supporting software [10].

\section{AUTOMOTIVE AND METALLURGICAL INDUSTRY STORAGE AND RETRIEVAL OPEARITONS IN SPECIFICATIONS}

It was mentioned in previous chapters that problematics of warehouse management is well treated in automotive industry. High demands on quality level in the automotive supply chains results into great effort spent on optimization of storage and retrieval operations in automotive distribution center. In this chapter the approaches, concepts and principles used in logistics processes in automotive industry will be presented. Also, the differences, characteristics and specifications of logistics processes in automotive and metallurgical industry will be presented. It is unnecessary to develop completely new methods for optimization storage and retrieval operations in the metallurgical industry. It is possible to take verified methods from automotive industry and adjust them for use in metallurgical industry. General specifications of logistics in automotive industry are listed below:

- $\quad$ logistics concepts (Lean, JIT/JIS, Kanban, TOC, TQM),

- $\quad$ standardized manipulation units (pallets, crates, boxes, containers),

- $\quad$ automated storage and retrieval systems,

- large and complicated input material flows,

- complicated supply of assembly lines,

- autonomous manipulation units. 
Present automotive companies pursue the idea of leanness, which leads to elimination of storage activities that are not considered as value adding. Stored products and material have number of characteristics that must be considered in process of storage location and zones assignment in warehouses. There are three main methods for storage location assignment dedicated or fixed storage, randomized or variable storage and classbased storage. The warehouse operations in the metallurgical company is characterized mainly by the large weights, measures and volumes of the manipulated products. The metallurgical industry is materialintensive and in order to ensure the continuous production it is necessary to maintain significant volumes of a variety of material. Due to very energy-intensive nature of metallurgical production, it is important to prevent any shortcomings leading to the shutdown of production. This urges the companies to hold a significant emergency supply of all necessary input materials. This leads to high demands on stock storage. Metallurgical companies are characterized by holding large volumes of stocks in the form of input material, semi-finished products, unfinished production, which binds a lot of capital and additionally creates high costs associated with stock storage and warehouse maintenance.

\section{MULTI CRITERIA INVENTORY CLASSIFICATION IN METALLURGICAL INDUSTRY}

The fundamental difference of this work from studies with similar focus is the nature of the examined metallurgical industry processes. This study is significant with the purpose of reorganizing the warehouse layout and product allocation, while most authors have as their main optimization of order picking system. Additional goals of this study are optimizing expedition processes, storage space utilization and streamlining of the placement of finished products. The proposed solution will be dynamic and will therefore recalculate all inputs, parameters and variables based on current data and provide an almost optimal solution. In the metallurgical industry there a specific characteristic that affects the product allocation such as type of product, measures of product, the weight of bundle, type of bundle, product turnover rate, contract, customer and type of expedition. Whole portfolio of stored products must be analysed in terms of all characteristics and criteria for future categorization of products for implementation of class-based storage. Result of analysis is categorization of products into classes according to all considered criteria. It was found that the main factors influencing the decision-making process in storage location assignment are loading process (means of transport, loading specifics), costumer (average order size, behavior, contract), product characteristics (type, quality, quantity, length), expedition plans, warehouse occupancy, date of deposition/expedition, storage method, turnover rate, hourly performance/production and average loading time. During the study the specifics and limitations resulting from the nature of metallurgical production were identified. Some of the limitations are unbalanced in truck dispatch, insufficient storage and handling capacity, insufficient integration of information systems, unsuitable infrastructure, enormous dimension and weight of products, large production batches, a wide portfolio of manufactured products. Categorization of stored products by the $A B C / X Y Z$ analysis for each considered criteria serves as foundation for design of tool for support of decision-making process in product storage location assignment.

\section{CONCLUSION}

Principles and methods presented in this paper are part of foundation for the proposal of a new methodology for the storage location assignment of products in the expedition warehouse of the metallurgical company. The characteristics and specifications of storage and expedition processes in the metallurgical industry were defined. During the analysis of the process of product storage the greatest potential for improvement was identified in the storage location assignment process, mainly in related decision-making. For design of a support tool for the decision-making process, the whole product portfolio and all storage locations were analysed and categorized. Many factors influencing the decision-making process were identified and analysed. Study results will be used to describe the problematic, collect input data, current system shortcomings identifications and create a concept for a proposal of a new methodology for product 
storage assignment. The proposed model should serve as a supporting tool used by expedition warehouse managers for the organization of the warehouse layout. The usage of the model will allow workers to make better decisions based on relevant and actual information. The purpose of the model will be to give a recommendation of the optimal storage location for the currently manufactured type of product. In future research it will be necessary to analyse the key factors influencing examined decision-making process in more detail and define the priorities and acceptable intervals of values. The priorities of the company management change dynamically and so it is necessary for the designed methodology to be flexible. The standardization of the decision-making process related to product storage allocation and optimization of the warehouse layout will lead to savings of time and resources in consecutive order picking. Optimized warehouse operations improve the expedition processes and the level of the logistics services provided to the customer. A key elements of warehouse operations are the product storage and retrieval. Throughout the process of storage location assignment for a specific product, a number of criteria and potential storage locations must be considered. So, it is necessary to support this process with exact decision-making tools. The optimal methods of multicriteria decision-making for this task must be selected. The application of methods of multicriteria decision-making will improve the efficiency of product storage and retrieval operations leading to shorter order picking times and warehouse space utilization

\section{ACKNOWLEDGEMENTS}

The work was supported by the specific university research of Ministry of Education, Youth and Sports of the Czech Republic at VSB - Technical University of Ostrava, projects no. SP2020/61.

\section{REFERENCES}

[1] DE KOSTER R., LE-DUC T. and ROODBERGEN K. Design and control of warehouse order picking: A literature review, European Journal of Operational Research, 2007, vol. 182, no. 2, pp. 481-501. https://doi.org/10.1016/j.ejor.2006.07.009.

[2] LENORT, R. Production Logistics Concepts and Systems: Potential for Use in Metallurgical and Waste Processing Companies. Krakow: AGH University of Science and Technology Press, 2010.

[3] SAMOLEJOVA, A., LENORT, R., LAMPA, M. and SIKOROVA, A. Specifics of metallurgical industry for implementation of lean principles. Metalurgija. 2012, vol. 52, no. 3, pp. 373-376.

[4] VENKITASUBRAMONY, R., ADIL, G.K. Design of an order-picking warehouse factoring vertical travel and space sharing. The International Journal of Advanced Manufacturing Technology. 2017, vol. 91, pp. 1921-1934. https://doi.org/10.1007/s00170-016-9879-3.

[5] ENE, S., ÖZTURK, N. Storage location assignment and order picking optimization in the automotive industry. The International Journal of Advanced Manufacturing Technology. 2012, vol. 60, pp. 787797.https://doi.org/10.1007/s00170-011-3593-y

[6] FONTANA, M. E., CAVALCANTE, C. A. V. Use of Promethee method to determine the best alternative for warehouse storage location assignment. The International Journal of Advanced Manufacturing Technology. 2014, vol. 70, pp. 1615-1624. https://doi.org/10.1007/s00170-013-5405-z

[7] JAWAHAR, N., ARAVINDAN, P. \& PONNAMBALAM, S.G. Optimal random storage allocation for an AS/RS in an FMS. The International Journal of Advanced Manufacturing Technology. 1998, vol. 14, pp. 116-132. https://doi.org/10.1007/BF01322220

[8] BALAJI K. and KUMAR V., Multicriteria Inventory ABC Classification in an Automobile Rubber Components Manufacturing Industry, Procedia CIRP. 2014, vol. 17, pp. 463-468. https://doi.org/10.1016/j.procir.2014.02.044.

[9] MANZINI, R., GAMBERI, M., PERSONA, A. et al. Desigon of a Class Based Storage Picker to Product Order Picking System. The International Journal of Advanced Manufacturing Technology. 2007, vol. 32, pp.811-821. https://doi.org/10.1007/s00170-005-0377-2

[10] ŠAFRÁNEK, M., and SIKOROVÁ, A. Improvement Of Effectivness Of Products Placing And Dispatch In The Dispatch Warehouse Of The Rough Rolling Plant. Acta Logistica. 2018, vol. 5, no. 2, pp. 53-57. doi: http://dx.doi.org/10.22306/al.v5i2.94 